\title{
Platform Therapy Compared with Natalizumab for Multiple Sclerosis: Relapse Rates and Time to Relapse Among Propensity Score-Matched US Patients
}

\author{
Barbara H. Johnson ${ }^{1} \cdot$ Machaon M. Bonafede ${ }^{1} \cdot$ Crystal Watson $^{2}$
}

Published online: 26 June 2015

(C) The Author(s) 2015. This article is published with open access at Springerlink.com

\begin{abstract}
Background Multiple sclerosis (MS) registry data, primarily from Europe, suggest that treatment with natalizumab delays time to relapse compared with platform therapy (interferon beta/glatiramer acetate).

Objective This study uses US administrative claims data and propensity score matching (PSM) to compare relapse rates and time to relapse among patients with MS using either platform therapy or natalizumab.

Methods Adults with MS receiving either platform therapy or natalizumab between January 1, 2009 and April 1, 2012 were identified in the Truven Health MarketScan ${ }^{\circledR}$ Research Databases. Patients were included if they had 12 months of continuous enrollment both before and after the index date (the first claim for either drug cohort) and had 12 months of claims data suggesting consistent treatment adherence during the follow-up period. Characteristics used in PSM included demographics, selected comorbidities and concomitant medications, MS severity, baseline relapse rates, and expenditures. A relapse was defined as an MS-related hospitalization or corticosteroid use.

Results A total of 882 patients were matched. Relapse occurred among significantly fewer patients in the natalizumab group $(26.5 \%)$ than platform therapy $(35.5 \%$, $p<0.001$ ) (hazard ratio $0.69 ; 95 \%$ CI $0.59-0.82$ ).
\end{abstract}

Barbara H. Johnson

barbara.h.johnson@truvenhealth.com

1 Life Sciences, Truven Health Analytics, 150 Cambridge Park Drive, Cambridge, MA 02140, USA

2 Health Economics and Outcomes Research, Biogen, Cambridge, MA, USA
Relapses were also significantly later for those on natalizumab (308 vs 283 days without relapse, $p<0.001$ ).

Conclusion Treatment with natalizumab was associated with a significantly lower risk and rate of MS relapse and longer MS relapse-free time compared with platform therapies.

\section{Key Points}

To our knowledge, this is the first US administrative claims study of natalizumab compared with platform therapy for MS (interferon beta/glatiramer acetate).

Patients on natalizumab experienced fewer relapses compared with patients on platform therapy (26.5 vs $35.5 \%, p<0.001)$.

Patients on natalizumab had longer relapse-free periods compared with patients on platform therapy (308 vs 283 days, $p<0.001$ ).

\section{Introduction}

Multiple sclerosis (MS) is a leading cause of disability among young adults, affecting approximately 400,000 people in the US and 2.5 million worldwide [1, 2]. Research has shown that early treatment with an FDAapproved disease-modifying therapy (DMT) following an MS diagnosis reduces the severity and frequency of relapses and some therapies may slow worsening of disease [3]. Several factors that influence which DMT a patient 
initiates include the desired clinical outcome, the patient's risk-benefit profile and the patient's preference for route and frequency of administration. In the phase III AFFIRM (natalizumab safety and efficacy in relapse-remitting MS) trial, natalizumab, when compared to placebo, showed a $68 \%$ reduction in annual relapse rate at 2 years and a $42 \%$ reduction in the risk of disability progression confirmed at 12 weeks [4]. Platform therapies (interferon beta (IFN $\beta$ )$1 \mathrm{a}$, IFN $\beta-1 \mathrm{~b}$ and glatiramer acetate) have also been shown to be efficacious by achieving an approximate $30 \%$ reduction in the annual relapse rate versus placebo, but not all platform therapies have shown a significant reduction in disability progression [5-7].

Few studies have attempted to evaluate disability worsening outside of a clinical trial, and over a longer follow-up period. One retrospective analysis of the AFFIRM study by Havrdova et al. reported that over a 2-year study period, $64 \%$ of natalizumab patients were free of clinical disease activity, $58 \%$ were free of radiological disease activity and $37 \%$ were free of combined activity $(p<0.0001)$ [8]. In a recent health resource utilization study, Bonafede et al. demonstrated that the results from clinical trials often translate well to real-world reductions in utilization [9]. In the 12 months following natalizumab initiation, $68.5 \%$ fewer patients experienced an MS-related inpatient admission and half as many $(50.6 \%)$ required corticosteroids. In a prospective observational study of MS patients from two Italian MS centers, Prosperini et al. found that escalating to natalizumab resulted in a significant reduction in relapse compared with switching among platform therapies [10]. In a retrospective observational study analyzing data from three Italian MS center databases, Lanzillo et al. reported that patients who switched to natalizumab from platform therapy experienced a significant reduction in the annualized relapse rate over the 12-month follow-up period [11].

While observational studies present more realistic data than those obtained from randomized clinical trials (RCTs), they are subject to selection bias. For instance, in the Lanzillo study, patients with certain clinical or demographic characteristics were more likely to be switched to natalizumab. To counter these confounding effects, Spelman et al. used propensity scores to match the comparison groups on characteristics such as disability, disease duration, and relapse history to report the effectiveness of natalizumab compared with platform therapy in a realworld population using data from MS registries, largely in Europe. Consistent with previous literature, patients in this matched population who switched from platform therapy to natalizumab had significantly longer time to relapse than patients who switched to a different platform therapy [12].

To our knowledge, this study is the first to corroborate these European findings with US administrative claims data. We used propensity score matching (PSM) to compare relapse rates and time to relapse among commercially insured patients with MS who were administered platform therapy or natalizumab for 12 months.

\section{Materials and Methods}

The Truven Health MarketScan ${ }^{\circledR}$ Commercial and Medicare Supplemental Databases were used to identify adults initiating platform therapy (interferon beta/glatiramer acetate) or natalizumab between January 1, 2009 and April 1, 2012. The first claim with a National Drug Code (NDC) or Healthcare Common Procedure Coding System (HCPCS) code for these drugs was designated as the index date, and the study period spanned January 1, 2008 to March 31, 2013. The MarketScan ${ }^{\circledR}$ Commercial Claims and Encounters Database consists of employer- and health plan-sourced medical and drug data. Over 43 million individuals are included in the 2012 database, comprising employees, their spouses, and dependents covered by employer-sponsored private health insurance. Medical claims are linked to outpatient prescription drug claims and person-level enrollment information. The MarketScan ${ }^{\circledR}$ Medicare Supplemental Database profiles the healthcare experience of retirees with Medicare supplemental insurance paid for by employers. It includes the Medicarecovered portion of payment, the employer-paid portion, and any out-of-pocket patient expenses. Over 4 million individuals are included in the 2012 database.

Patients were included if they had a medical claim with an International Classification of Diseases, ninth revision, clinical modification (ICD-9-CM) diagnosis code for MS (ICD-9-CM code 340) during the 12 months prior to the index date (pre-period). Patients were also required to have medical and prescription claims history and continuous eligibility during the pre-period and for the 12 months following the index date (post-period). Patients were required to remain on their index drug for the entire 12-month post-period, which was verified by the presence of at least one claim for the index drug in each of the 12 follow-up months. Patients who had claims with a diagnosis of pregnancy or delivery during any point in the preor post-period and those with evidence of using a nonindex MS therapy in the pre-period were excluded from the analysis. Platform therapies consisted of the following DMTs: IFN $\beta-1 \mathrm{a} \quad\left(\right.$ AVONEX $^{\circledR}, \quad$ REBIF $\left.^{\circledR}\right), \quad$ IFN $\beta-1 \mathrm{~b}$ $\left(\right.$ BETASERON $^{\circledR}$, EXTAVIA ${ }^{\circledR}$ ), and glatiramer acetate $\left(\mathrm{COPAXONE}^{\circledR}\right)$. Natalizumab was listed as brand-name TYSABRI $^{\circledR}$.

Demographic and clinical characteristics were captured for the index date and during the pre-period, respectively. Demographic characteristics included age, gender, 
geographic region, health insurance plan type and urbanicity. Comorbidities and concomitant medications during the pre-period were also described and included those common in patients with MS (e.g., bladder dysfunction, fatigue, headache, other chronic pain, depression, and use of corticosteroids, benzodiazepine, muscle relaxants, antispasmodics and antidepressants).

The patient's MS severity was measured using a claimsbased algorithm adapted from Kurtzke's Functional System (KFS) [13]. The algorithm assigns a weight (1-6) to each of the measures in Kurtzke's FS using ICD-9-CM codes on administrative claims (and for one measure, prescription claims) which correspond to each measure in seven out of the eight functional systems. For example, one measure of pyramidal functions is "abnormal signs without disability"; this was recorded if a patient had a claim coded to ICD-9-CM 781.2 (abnormality of gait), and assigned a weight of 1 . A more severe measure, "the inability to swallow or speak" in brainstem functions, was recorded if a patient had a claim coded to ICD-9-CM 438.82 (other late effects of cerebrovascular disease, dysphagia), 787.2x (dysphagia) or v41.6 (problems with swallowing and mastication) and assigned a weight of 5 . The sum of a patient's weights across the 65 measures of function thus generated a severity score.

To adjust for differences in patient profiles which may confound findings, PSM using a logistic regression model was conducted on the probability of a patient receiving natalizumab. Patients in the natalizumab treatment arm were matched $1: 1$ to the pool of patients in the platform treatment arm with a similar predicted probability using the nearest neighbor matching technique with a caliper of 0.25 standard deviations (SD) of the propensity score. Matching factors included age, gender, region, health plan type, index year, selected comorbidities and concomitant medications, MS severity, pre-period relapse (binary variable indicating presence of an MS-related inpatient admission or use of corticosteroids), and pre-period expenditures. To examine the quality of the match, we calculated the standardized difference, which does not depend on sample size. The match was considered successful if the standardized difference was $<10$ for the majority of matching factors [14].

Post-period outcome measures consisted of relapse rate and time to relapse. Relapse was defined using an adaptation of a claims-based algorithm first described by Ollendorf et al. [15] and subsequently validated by Chastek and colleagues [16]. The presence of any of the following during the post-period indicated relapse: an MS-related inpatient stay (hospitalization with ICD-9-CM 340 as the primary diagnosis), or intravenous (IV) or oral corticosteroid use. Time to relapse was calculated as the number of days from the index date until the earliest occurrence of a relapse. This outcome was evaluated using a univariate Cox Proportional Hazard model to compare the time to relapse between the group who received platform therapy and those who received natalizumab. A sensitivity analysis was performed using a Cox Proportional Hazard model adjusting for the following confounders: age, gender, preperiod MS-related inpatient admissions, pre-period corticosteroid use (any, IV, oral), pre-period expenditures and MS severity. Multicollinearity of the independent variables was tested by calculating the variance inflation factor (VIF). The Schoenfeld test and a variety of graphical methods were used to verify that all variables met the proportionality assumption of the Cox modeling approach.

\section{Results}

The total sample comprised 897 natalizumab patients and 6605 platform therapy patients who met all study inclusion and exclusion criteria. After 1:1 matching, 882 natalizumab patients (mean age 45.4 [SD 10.0] years, $69 \%$ female) were matched to 882 platform therapy patients (mean age 45.3 [SD 10.5] years, $70 \%$ female). Over one-third of patients (35-37\%) had evidence of other chronic pain, more than one in four had a headache diagnosis and at least $16 \%$ had been diagnosed with bladder dysfunction, depression or fatigue. Approximately half of the final study sample (49-52\%) had been prescribed antidepressants and up to $40 \%$ had prescriptions for muscle relaxants (37-41\%), corticosteroids (37-39\%), benzodiazepines $(32-33 \%)$ and anti-spasmodic agents (30-35\%). Cohorts were well matched with standardized differences $<10$ for all matching factors (Table 1).

Individual measures within the seven functional systems differed between the two cohorts before matching, with a greater proportion of platform patients having a disturbance of skin sensation ( 21.4 vs $8.7 \%)$ and a lower proportion having abnormality of gait $(8.3$ vs $10.5 \%)$ and a prescription for dalfampridine ( 0.3 vs $2.2 \%$ ) compared with natalizumab. After matching, the proportions of patients with these characteristics were similar (9.6 vs $8.8 \%, 9.8$ vs $10.3 \%$ and 0.9 vs $1.9 \%$, platform vs natalizumab, respectively) (Fig. 1).

After matching, significantly fewer natalizumab patients experienced post-period relapses compared with those on platform therapy ( 26.5 vs $35.5 \%, p<0.001)$. Natalizumab patients had a significantly lower risk of relapse (hazard ratio [HR] 0.695; $95 \%$ confidence interval [CI] 0.59-0.82) during the 12-month post-period; the adjusted Cox model yielded the same result (HR 0.693; $95 \%$ CI 0.59-0.82) (Table 2; Fig. 2). Duration of relapse-free time was also longer for the natalizumab patients; they experienced 25 more days without a relapse during the 12 -month post- 
Table 1 Baseline demographic and clinical characteristics pre- and post-propensity score matching

\begin{tabular}{|c|c|c|c|c|c|c|c|c|c|c|}
\hline \multirow[t]{3}{*}{ Variables } & \multicolumn{5}{|c|}{ Pre-match } & \multicolumn{5}{|c|}{ Post-match } \\
\hline & \multicolumn{2}{|c|}{$\begin{array}{l}\text { Platform } \\
\text { therapy } \\
N=6605\end{array}$} & \multicolumn{2}{|c|}{$\begin{array}{l}\text { Natalizumab } \\
N=897\end{array}$} & \multirow[t]{2}{*}{$\begin{array}{l}\text { Standardized } \\
\text { difference }\end{array}$} & \multicolumn{2}{|c|}{$\begin{array}{l}\text { Platform } \\
\text { therapy } \\
N=882\end{array}$} & \multicolumn{2}{|c|}{$\begin{array}{l}\text { Natalizumab } \\
N=882\end{array}$} & \multirow[t]{2}{*}{$\begin{array}{l}\text { Standardized } \\
\text { difference }\end{array}$} \\
\hline & $\begin{array}{l}N / \\
\text { mean }\end{array}$ & $\% / S D$ & $\begin{array}{l}N / \\
\text { mean }\end{array}$ & $\% / S D$ & & $\begin{array}{l}N / \\
\text { mean }\end{array}$ & $\% / S D$ & $\begin{array}{l}N / \\
\text { mean }\end{array}$ & $\% / \mathrm{SD}$ & \\
\hline Age (mean, SD) & 47.7 & 10.5 & 45.3 & 10.0 & 23.41 & 45.3 & 10.5 & 45.4 & 10.0 & -0.72 \\
\hline \multicolumn{11}{|l|}{ Age range $(N, \%)$} \\
\hline $18-34$ & 769 & $11.6 \%$ & 135 & $15.1 \%$ & -10.03 & 146 & $16.6 \%$ & 130 & $14.7 \%$ & 4.99 \\
\hline $35-44$ & 1664 & $25.2 \%$ & 286 & $31.9 \%$ & -14.86 & 275 & $31.2 \%$ & 278 & $31.5 \%$ & -0.73 \\
\hline $45-54$ & 2318 & $35.1 \%$ & 300 & $33.4 \%$ & 3.48 & 281 & $31.9 \%$ & 299 & $33.9 \%$ & -4.35 \\
\hline $55-64$ & 1618 & $24.5 \%$ & 162 & $18.1 \%$ & 15.78 & 165 & $18.7 \%$ & 161 & $18.3 \%$ & 1.17 \\
\hline $65+$ & 236 & $3.6 \%$ & 14 & $1.6 \%$ & 12.75 & 15 & $1.7 \%$ & 14 & $1.6 \%$ & 0.89 \\
\hline Female $(N, \%)$ & 4911 & $74.4 \%$ & 622 & $69.3 \%$ & 11.16 & 618 & $70.1 \%$ & 611 & $69.3 \%$ & 1.73 \\
\hline \multicolumn{11}{|l|}{ Geographic region $(N, \%)$} \\
\hline Northeast & 1112 & $16.8 \%$ & 147 & $16.4 \%$ & 1.20 & 140 & $15.9 \%$ & 145 & $16.4 \%$ & -1.54 \\
\hline Mid West & 2077 & $31.4 \%$ & 259 & $28.9 \%$ & 5.61 & 251 & $28.5 \%$ & 255 & $28.9 \%$ & -1.00 \\
\hline South & 2018 & $30.6 \%$ & 336 & $37.5 \%$ & -14.62 & 335 & $38.0 \%$ & 331 & $37.5 \%$ & 0.94 \\
\hline West & 1359 & $20.6 \%$ & 148 & $16.5 \%$ & 10.50 & 151 & $17.1 \%$ & 144 & $16.3 \%$ & 2.13 \\
\hline Unknown & 39 & $0.6 \%$ & 7 & $0.8 \%$ & -2.30 & 5 & $0.6 \%$ & 7 & $0.8 \%$ & -2.76 \\
\hline Rural residence $(N, \%)$ & 976 & $14.8 \%$ & 108 & $12.0 \%$ & 8.04 & 128 & $14.5 \%$ & 108 & $12.2 \%$ & 6.66 \\
\hline \multicolumn{11}{|l|}{ Insurance type $(N, \%)$} \\
\hline Comprehensive & 229 & $3.5 \%$ & 30 & $3.3 \%$ & 0.68 & 34 & $3.9 \%$ & 30 & $3.4 \%$ & 2.43 \\
\hline HMO & 1419 & $21.5 \%$ & 114 & $12.7 \%$ & 23.47 & 121 & $13.7 \%$ & 111 & $12.6 \%$ & 3.36 \\
\hline POS & 403 & $6.1 \%$ & 85 & $9.5 \%$ & -12.62 & 80 & $9.1 \%$ & 82 & $9.3 \%$ & -0.79 \\
\hline PPO or EPO & 3959 & $59.9 \%$ & 594 & $66.2 \%$ & -13.04 & 582 & $66.0 \%$ & 585 & $66.3 \%$ & -0.72 \\
\hline CDHP or HDHP & 262 & $4.0 \%$ & 41 & $4.6 \%$ & -2.99 & 35 & $4.0 \%$ & 41 & $4.6 \%$ & -3.35 \\
\hline Other/unknown & 333 & $5.0 \%$ & 33 & $3.7 \%$ & 6.68 & 30 & $3.4 \%$ & 33 & $3.7 \%$ & -1.83 \\
\hline \multicolumn{11}{|c|}{ Common comorbid conditions $(N, \%)$} \\
\hline Bladder dysfunction & 724 & $11.0 \%$ & 145 & $16.2 \%$ & -15.24 & 143 & $16.2 \%$ & 140 & $15.9 \%$ & 0.93 \\
\hline Depression & 734 & $11.1 \%$ & 135 & $15.1 \%$ & -11.70 & 142 & $16.1 \%$ & 132 & $15.0 \%$ & 3.13 \\
\hline Fatigue & 899 & $13.6 \%$ & 127 & $14.2 \%$ & -1.58 & 148 & $16.8 \%$ & 127 & $14.4 \%$ & 6.57 \\
\hline $\begin{array}{l}\text { Gastrointestinal disease and } \\
\text { symptoms }\end{array}$ & 719 & $10.9 \%$ & 99 & $11.0 \%$ & -0.48 & 103 & $11.7 \%$ & 98 & $11.1 \%$ & 1.78 \\
\hline Headache & 1880 & $28.5 \%$ & 238 & $26.5 \%$ & 4.32 & 254 & $28.8 \%$ & 234 & $26.5 \%$ & 5.07 \\
\hline High blood pressure & 1485 & $22.5 \%$ & 161 & $17.9 \%$ & 11.31 & 154 & $17.5 \%$ & 161 & $18.3 \%$ & -2.07 \\
\hline Neuropathic pain & 870 & $13.2 \%$ & 73 & $8.1 \%$ & 16.37 & 75 & $8.5 \%$ & 72 & $8.2 \%$ & 1.23 \\
\hline Other chronic pain & 2458 & $37.2 \%$ & 317 & $35.3 \%$ & 3.90 & 325 & $36.8 \%$ & 312 & $35.4 \%$ & 3.07 \\
\hline Urinary tract infection & 700 & $10.6 \%$ & 118 & $13.2 \%$ & -7.91 & 115 & $13.0 \%$ & 114 & $12.9 \%$ & 0.34 \\
\hline \multicolumn{11}{|l|}{ Concomitant medications $(N, \%)$} \\
\hline Anti-depressants & 2427 & $36.7 \%$ & 445 & $49.6 \%$ & -26.19 & 461 & $52.3 \%$ & 435 & $49.3 \%$ & 5.90 \\
\hline Anti-spasmodic agents & 1011 & $15.3 \%$ & 278 & $31.0 \%$ & -37.85 & 305 & $34.6 \%$ & 268 & $30.4 \%$ & 8.97 \\
\hline Benzodiazepines & 1852 & $28.0 \%$ & 289 & $32.2 \%$ & -9.12 & 293 & $33.2 \%$ & 283 & $32.1 \%$ & 2.42 \\
\hline Corticosteroids & 2494 & $37.8 \%$ & 327 & $36.5 \%$ & 2.70 & 346 & $39.2 \%$ & 322 & $36.5 \%$ & 5.61 \\
\hline Oral & 1930 & $29.2 \%$ & 207 & $23.1 \%$ & 14.01 & 205 & $23.2 \%$ & 205 & $23.2 \%$ & 0.00 \\
\hline IV & 1196 & $18.1 \%$ & 209 & $23.3 \%$ & -12.84 & 229 & $26.0 \%$ & 205 & $23.2 \%$ & 6.32 \\
\hline Immunosuppressive agents & 115 & $1.7 \%$ & 17 & $1.9 \%$ & -1.15 & 21 & $2.4 \%$ & 17 & $1.9 \%$ & 3.12 \\
\hline Muscle relaxants & 1595 & $24.1 \%$ & 334 & $37.2 \%$ & -28.66 & 357 & $40.5 \%$ & 323 & $36.6 \%$ & 7.93 \\
\hline
\end{tabular}


Table 1 continued

\begin{tabular}{|c|c|c|c|c|c|c|c|c|c|c|}
\hline \multirow[t]{3}{*}{ Variables } & \multicolumn{5}{|c|}{ Pre-match } & \multicolumn{5}{|c|}{ Post-match } \\
\hline & \multicolumn{2}{|c|}{$\begin{array}{l}\text { Platform } \\
\text { therapy } \\
N=6605\end{array}$} & \multicolumn{2}{|c|}{$\begin{array}{l}\text { Natalizumab } \\
N=897\end{array}$} & \multirow[t]{2}{*}{$\begin{array}{l}\text { Standardized } \\
\text { difference }\end{array}$} & \multicolumn{2}{|c|}{$\begin{array}{l}\text { Platform } \\
\text { therapy } \\
N=882\end{array}$} & \multicolumn{2}{|c|}{$\begin{array}{l}\text { Natalizumab } \\
N=882\end{array}$} & \multirow[t]{2}{*}{$\begin{array}{l}\text { Standardized } \\
\text { difference }\end{array}$} \\
\hline & $N /$ mean & $\% / \mathrm{SD}$ & $\mathrm{N} / \mathrm{mean}$ & $\% / \mathrm{SD}$ & & $N /$ mean & $\% / \mathrm{SD}$ & $N /$ mean & $\% / \mathrm{SD}$ & \\
\hline $\begin{array}{l}\text { Baseline severity score } \\
\text { (mean, SD) }\end{array}$ & 0.8 & 1.5 & 0.7 & 1.6 & 3.57 & 0.7 & 1.7 & 0.7 & 1.6 & 2.44 \\
\hline Pre-period relapse $(N, \%)$ & 2593 & $39.3 \%$ & 333 & $37.1 \%$ & 4.39 & 358 & $40.6 \%$ & 328 & $37.2 \%$ & 6.98 \\
\hline $\begin{array}{l}\text { Pre-period expenditures } \\
\text { (mean US\$, SD) }\end{array}$ & 24,832 & 19,525 & 38,850 & 25,905 & -61.11 & 35,794 & 33,345 & 38,477 & 25,384 & 9.05 \\
\hline
\end{tabular}

$C D H P$ consumer driven health plan, $E P O$ exclusive provider organization, $H D H P$ high deductible health plan, $H M O$ health maintenance organization, $I V$ intravenous, $N$ number, $P O S$ point of service, $P P O$ preferred provider organization, $S D$ standard deviation

Fig. 1 Level of disability by functional system, pre- and post-propensity score matching

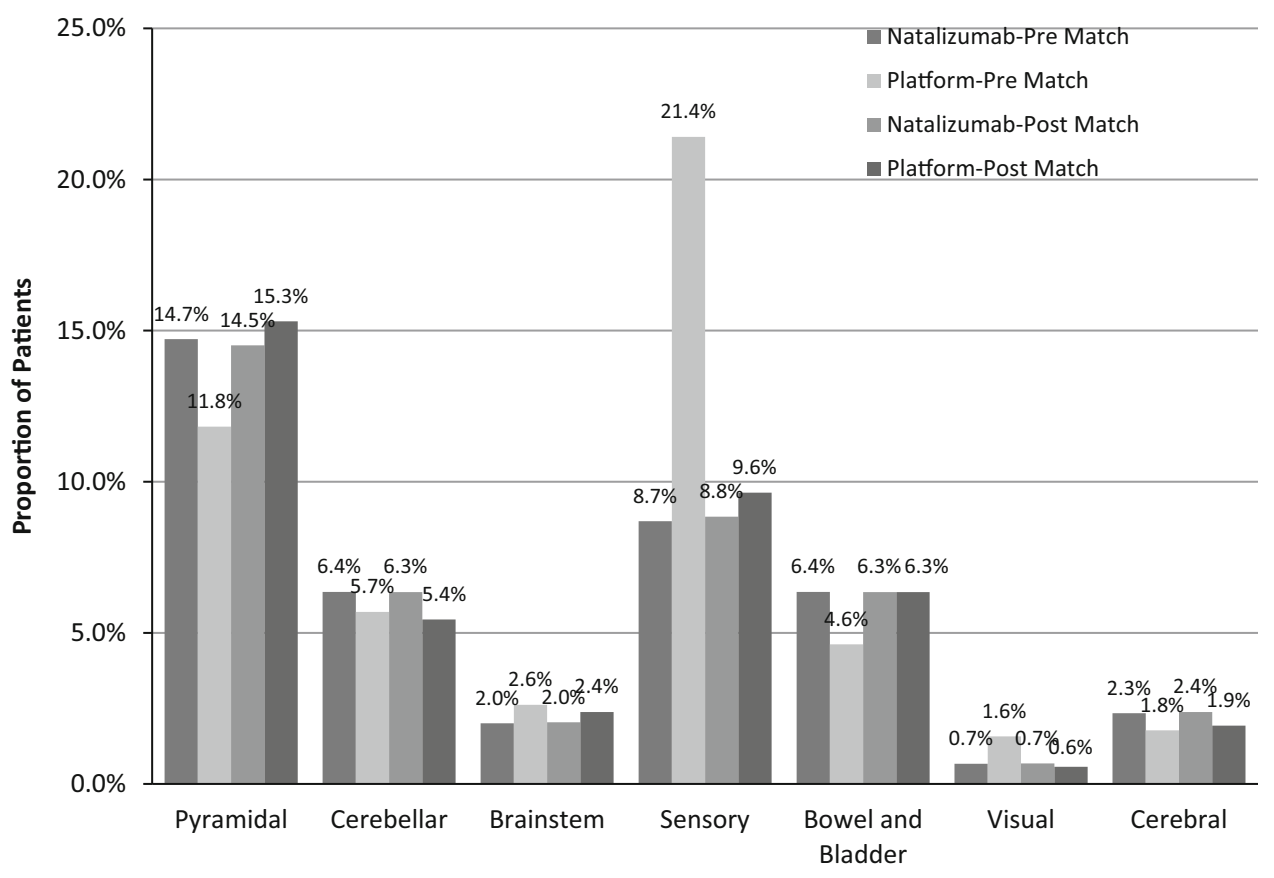

Kurtzke's Functional Systems period (308 vs 283 days, $p<0.001)$. Additionally, natalizumab patients had lower rates of MS-related inpatient admissions (1.0 vs $2.6 \%$ ), IV corticosteroid use (15.6 vs $19.0 \%)$ and oral corticosteroid use (15.4 vs $23.1 \%$ ) compared with platform therapy patients (all $p<0.001$ ).

Among propensity-matched patients, the presence of baseline corticosteroid use was associated with a significantly increased risk of relapse during the follow-up period (HR 2.0; $95 \%$ CI 1.42-2.88; $p<0.001$ ); however, there was no increased risk associated with baseline MS-related inpatient admissions (HR 1.1; $95 \%$ CI 0.73-1.56; $p=0.731)$. Overall, patients with an MS severity score $>0$ had an increased risk of relapse. Compared with patients 18-34 years of age, those 45-54 years of age were more likely to experience a relapse (HR 1.44; $95 \%$ CI $1.10-1.88 ; p=0.007)$. Higher pre-period expenditures were also associated with an increased risk of relapse (HR 1.16 ; $95 \%$ CI $1.03-1.30 ; p=0.014)$. In contrast, significant interactions were not seen for sex or among any of the other age groups.

\section{Discussion}

Findings from the current study suggest that initial treatment with natalizumab compared with platform therapy significantly reduces the risk of relapse among commercially insured patients in the US. Patients who were being 
Table 2 Time to relapse and relapse rates measured in the post period, pre- and post-propensity score matching

\begin{tabular}{|c|c|c|c|c|c|c|c|c|c|c|}
\hline \multirow[t]{3}{*}{ Relapse } & \multicolumn{4}{|c|}{ Pre-match } & \multirow[t]{3}{*}{$p$ value } & \multicolumn{4}{|c|}{ Post-match } & \multirow[t]{3}{*}{$p$ value } \\
\hline & \multicolumn{2}{|c|}{$\begin{array}{l}\text { Platform therapy } \\
N=6605\end{array}$} & \multicolumn{2}{|c|}{$\begin{array}{l}\text { Natalizumab } \\
N=897\end{array}$} & & \multicolumn{2}{|c|}{$\begin{array}{l}\text { Platform therapy } \\
N=882\end{array}$} & \multicolumn{2}{|c|}{$\begin{array}{l}\text { Natalizumab } \\
N=882\end{array}$} & \\
\hline & $\begin{array}{l}N / \\
\text { mean }\end{array}$ & $\% / \mathrm{SD}$ & $\begin{array}{l}N / \\
\text { mean }\end{array}$ & $\% / \mathrm{SD}$ & & $\begin{array}{l}N / \\
\text { Mean }\end{array}$ & $\% / \mathrm{SD}$ & $\begin{array}{l}N / \\
\text { mean }\end{array}$ & $\% / \mathrm{SD}$ & \\
\hline Time without relapse (mean, SD) & 297.5 & 118.0 & 307.7 & 110.9 & 0.015 & 283.0 & 127.6 & 307.7 & 110.8 & $<0.001$ \\
\hline Relapse $(N, \%)$ & 1997 & $30.2 \%$ & 240 & $26.8 \%$ & 0.033 & 313 & $35.5 \%$ & 234 & $26.5 \%$ & $<0.001$ \\
\hline Time to relapse in days (mean, SD) & 141.7 & 106.2 & 146.2 & 107.7 & 0.241 & 134.0 & 107.0 & 145.4 & 106.9 & 0.221 \\
\hline MS-related inpatient (IP) stay (N, \%) & 89 & $1.3 \%$ & 9 & $1.0 \%$ & 0.394 & 23 & $2.6 \%$ & 9 & $1.0 \%$ & $<0.001$ \\
\hline Time to MS-related IP stay (mean, SD) & 146.7 & 96.1 & 165.2 & 106.8 & $<0.001$ & 139.9 & 109.0 & 165.2 & 106.8 & 0.557 \\
\hline Any corticosteroid use $(N, \%)$ & 1,962 & $29.7 \%$ & 236 & $26.3 \%$ & 0.036 & 303 & $34.4 \%$ & 231 & $26.2 \%$ & $<0.001$ \\
\hline $\begin{array}{l}\text { Time to any corticosteroid use } \\
\text { (mean, SD) }\end{array}$ & 142.2 & 106.5 & 147.0 & 108.1 & 0.203 & 134.4 & 107.4 & 146.2 & 107.3 & 0.210 \\
\hline IV corticosteroid use $(N, \%)$ & 953 & $14.4 \%$ & 141 & $15.7 \%$ & 0.304 & 168 & $19.0 \%$ & 138 & $15.6 \%$ & $<0.001$ \\
\hline $\begin{array}{l}\text { Time to IV corticosteroid use } \\
\text { (mean, SD) }\end{array}$ & 149.8 & 109.0 & 150.5 & 103.7 & 0.860 & 134.9 & 109.8 & 151.4 & 103.2 & 0.180 \\
\hline Oral corticosteroid use $(N, \%)$ & 1437 & $21.8 \%$ & 138 & $15.4 \%$ & $<0.001$ & 204 & $23.1 \%$ & 136 & $15.4 \%$ & $<0.001$ \\
\hline $\begin{array}{l}\text { Time to oral corticosteroid use } \\
\text { (mean, SD) }\end{array}$ & 150.0 & 106.5 & 167.9 & 116.6 & $<0.001$ & 146.8 & 106.4 & 166.0 & 116.2 & 0.117 \\
\hline
\end{tabular}

$I V$ intravenous, $M S$ multiple sclerosis, $N$ number, $S D$ standard deviation

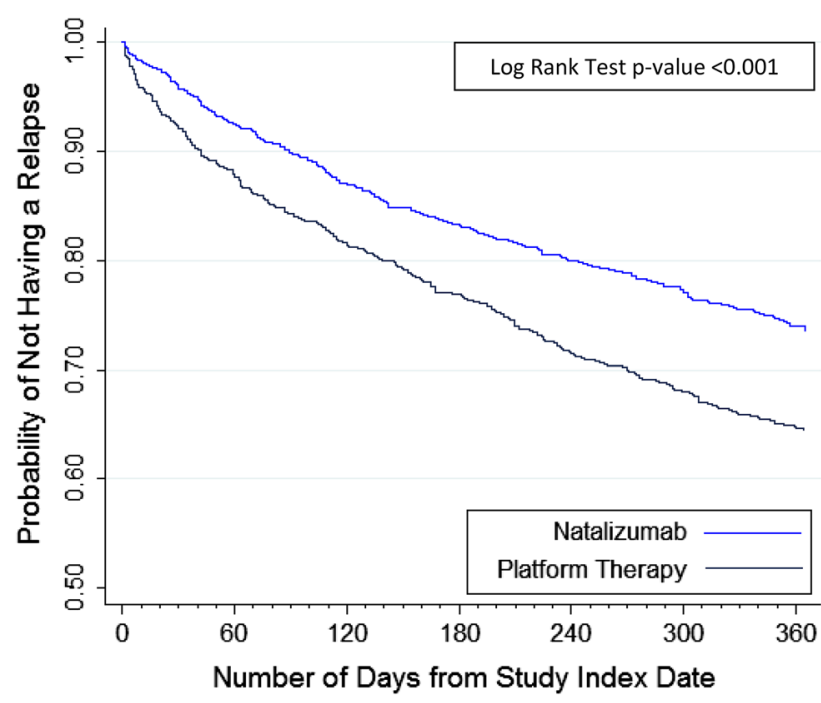

Fig. 2 Probability of no relapse among propensity score-matched patients: natalizumab versus platform therapy

treated with platform therapy were $34 \%$ more likely to have a relapse compared with those treated with natalizumab. Patients on natalizumab went nearly a month longer without relapse compared with matched patients on platform therapy. During the 12-month post-period, patients on natalizumab had significantly fewer MS-related inpatient admissions and significantly less corticosteroid use than their matched platform therapy counterparts.
These findings are consistent with a similar comparison among propensity-score-matched patients across two separate MS registries in which patients who switched to natalizumab had an annualized relapse rate $83 \%$ lower than those who remained on platform therapy [12]. In an analysis of MS patients initiating or switching to natalizumab, Bonafede et al. reported similar findings to the current study [9]. Significant reductions in MS-related inpatient admissions and corticosteroid use were noted during a 12-month follow-up period for both initiators and switchers (77.1 and $44.7 \%$ reduction in admissions; 64.5 and $52.5 \%$ reduction in corticosteroid use, respectively) [9].

In this study, natalizumab and platform patients were substantively different in terms of disease severity and baseline demographics and clinical characteristics prior to matching. Differences in baseline characteristics suggests (but does not confirm) the presence of channeling bias whereby more complicated or severe patients may have been channeled to natalizumab instead of platform therapies. Similar differences in patient characteristics prior to matching were also described by Spelman et al. [12] According to Spelman et al., baseline differences in the unmatched cohorts significantly impacted the study outcome of relapse rate as natalizumab patients had significantly greater disease severity.

Our findings are also supported by results of the phase III AFFIRM study in which the annualized relapse rate for 
patients on natalizumab compared with those on placebo decreased by $68 \%$ at year 1 [4]. Furthermore, in their interim analysis of the ongoing TOP (Tysabri Observational Program) prospective observational study, Butzkueven et al. reported that the mean annualized relapse rate decreased significantly in the first year after natalizumab treatment and was lower for those patients who used natalizumab as their first treatment [17]. In their prospective observational study, Prosperini et al. compared patients who switched from platform therapy to natalizumab with patients who switched from one platform therapy to another [10]. Prosperini reported that a lower proportion of patients who escalated to natalizumab experienced a relapse compared with those who switched to a different platform therapy. A similar result was present in this current analysis, suggesting better effectiveness with natalizumab versus platform therapy for treatment-naïve or previously treated patients after controlling for differences in patient and disease severity characteristics among platform and natalizumab users.

\section{Limitations}

Several limitations are noteworthy. First, the study population in our analysis is limited to those individuals with commercial health coverage or private Medicare supplemental coverage. Consequently, results of this analysis may not be generalizable to MS patients with other insurance or without health insurance coverage. Secondly, as with any claims databases, the MarketScan Research Databases rely on administrative claims data for clinical detail, some of which is missing because it is not captured in claims and are subject to data coding limitations and data entry error. Although the Kurtzke's FS score was used as a proxy to determine severity, other key clinical measures are not available in claims data, so the cohorts could not be matched for all disease severity measures. Additionally, the KFS algorithm is currently experimental and future planned work includes validating the algorithm. Thirdly, the number of relapse events captured is likely to be an underestimate as the criteria (evidence of MS-related hospitalization or IV/ oral corticosteroid use) did not capture less severe relapses that would not have resulted in a hospitalization or corticosteroid use. Fourthly, the patients in the current study were required to stay on therapy for the 12-month postperiod, so patients who discontinued therapy or switched to another therapy within the 12-month post-period were not analyzed. Fifthly, pre-index exposure to other MS-specific disease-modifying treatments was not included in the match as the study design (and data source) is not adequate to define total time on DMT therapy or time since MS diagnosis as they contain only a relatively short portion of patient-time for the MS patient. Sixthly, because administrative claims data were used, we were unable to examine relapse or time to relapse for different types of MS (e.g., remitting-relapsing, secondary progressive), which are not distinguished in the ICD-9-CM coding. Lastly, the inferences drawn by this study are reliant upon the data available for inclusion in the PSM and multivariate analysis. We could not assess if differences in unobserved characteristics between the treatment cohorts might impact the study results or conclusions.

\section{Conclusion}

Use of natalizumab for MS was associated with significantly lower risk and rate of relapse compared with treatment with IFN $\beta /$ glatiramer acetate (platform therapy) among propensity score-matched patients. Natalizumab patients also had significantly more relapse-free time than platform patients during the 12-month follow-up period.

Acknowledgments The authors wish to acknowledge Bong Chul Chu for his statistical contributions to the study.

\section{Compliance with Ethical Standards}

Funding Truven Health Analytics was awarded a research contract by Biogen to conduct this study. Open Access was funded by Biogen.

Conflicts of interest Two authors (BHJ and MMB) are employees of Truven Health Analytics. The third author (CW) is an employee and shareholder of Biogen.

Open Access This article is distributed under the terms of the Creative Commons Attribution-NonCommercial 4.0 International License (http://creativecommons.org/licenses/by-nc/4.0/), which permits any noncommercial use, distribution, and reproduction in any medium, provided you give appropriate credit to the original author(s) and the source, provide a link to the Creative Commons license, and indicate if changes were made.

\section{References}

1. Pelletier D, Hafler DA. Fingolimod for multiple sclerosis. N Engl J Med. 2012;366:339-47.

2. Kantarci OH, Pirko I, Rodriguez M. Novel immunomodulatory approaches for the management of multiple sclerosis. Clin Pharmacol Ther. 2014;95:32-44.

3. Elovaara I. Early treatment in multiple sclerosis. J Neurol Sci. 2011;311(Suppl 1):S24-8.

4. Polman $\mathrm{CH}$, O'Connor PW, Havrdova E, et al. A randomized, placebo-controlled trial of natalizumab for relapsing multiple sclerosis. N Engl J Med. 2006;354:899-910.

5. Goodin DS, Cohen BA, O'Connor P, Kappos L, Stevens JC. Assessment: the use of natalizumab (Tysabri) for the treatment of multiple sclerosis (an evidence-based review): report of the Therapeutics and Technology Assessment Subcommittee of the American Academy of Neurology. Neurology. 2008;71:766-73. 
6. Nicholas JA, Racke MK, Imitola J, Boster AL. First-line natalizumab in multiple sclerosis: rationale, patient selection, benefits and risks. Ther Adv Chronic Dis. 2014;5:62-8.

7. Goodin DS, Frohman EM, Garmany GP Jr, et al. Disease modifying therapies in multiple sclerosis: report of the Therapeutics and Technology Assessment Subcommittee of the American Academy of Neurology and the MS Council for Clinical Practice Guidelines. Neurology. 2002;58:169-78.

8. Havrdova E, Galetta S, Hutchinson M, et al. Effect of natalizumab on clinical and radiological disease activity in multiple sclerosis: a retrospective analysis of the Natalizumab Safety and Efficacy in Relapsing-Remitting Multiple Sclerosis (AFFIRM) study. Lancet Neurol. 2009;8:254-60.

9. Bonafede MM, Johnson BH, Watson C. Health care-resource utilization before and after natalizumab initiation in multiple sclerosis patients in the US. Clinicoecon Outcomes Res CEOR. 2013;6:11-20.

10. Prosperini L, Gianni C, Leonardi L, et al. Escalation to natalizumab or switching among immunomodulators in relapsing multiple sclerosis. Mult Scler. 2012;18:64-71.

11. Lanzillo R, Bonavita $S$, Quarantelli $M$, et al. Natalizumab is effective in multiple sclerosis patients switching from other disease modifying therapies in clinical practice. Neurol Sci. 2013;34:521-8.
12. Spelman T, Pellegrini F, Zhang A, et al. Comparison of patients treated with natalizumab and interferon beta/glatiramer using propensity-matched multiple sclerosis registry data. The 65th Annual Meeting of the American Academy of Neurology. San Diego, CA; 2013.

13. Clinical Coulthard-Morris L, Measures Rehabilitation. In: Burks JS, Johnson KP, editors. Multiple sclerosis diagnosis, medical management, and rehabilitation. New York: Demos Medical Publishing Inc; 2000. p. 221-90.

14. Ho DE, Imai K, King G, Stuart EA. Matching as nonparametric preprocessing for reducing model dependence in parametric causal inference. Political Anal. 2007;15:199-236.

15. Ollendorf DA, Jilinskaia E, Oleen-Burkey M. Clinical and economic impact of glatiramer acetate versus beta interferon therapy among patients with multiple sclerosis in a managed care population. J Manag Care Pharm. 2002;8:469-76.

16. Chastek BJ, Oleen-Burkey M, Lopez-Bresnahan MV. Medical chart validation of an algorithm for identifying multiple sclerosis relapse in healthcare claims. J Med Econ. 2010;13:618-25.

17. Butzkueven H, Kappos L, Pellegrini F, et al. Efficacy and safety of natalizumab in multiple sclerosis: interim observational programme results. J Neurol Neurosurg Psychiatry. 2014;85:1190-7. 